\title{
Equilibrium and Kinetic Studies of Adsorption of Aqueous Crystal Violet by Peanut Shells
}

\author{
Hosne Ara Begum, Md. Ariful Islam and Tanvir Muslim \\ Department of Chemistry, University of Dhaka, Dhaka-1000, Bangladesh
}

Received: May 07, 2014; $\quad$ Accepted: May 26, 2014; $\quad$ Published (Web): July 23, 2014

\begin{abstract}
In the present study, the ability of a non-conventional biosorbent, peanut shells (PnS) for the removal of crystal violet $(\mathrm{CV})$, a cationic dye, from aqueous solution was evaluated. The surface zero point charge $\left(\mathrm{pH}_{\mathrm{zpc}}\right)$ of peanut shells was estimated and found to be 6.27. Batch adsorption experiments were performed and system variables were investigated including contact time, initial dye concentration, temperature and $\mathrm{pH}$ of the solution. The estimated equilibrium time was found to be 4 hours. The adsorption of $\mathrm{CV}$ on PnS was found to increase with the increment of initial concentration of $\mathrm{CV}$ solution and $\mathrm{pH}$ of the medium. The equilibrium adsorption data were fitted to the Langmuir and Freunlich isotherms. The best result was achieved with Langmuir isotherm model. The adsorption rates were found to be consistent with a pseudo-second-order model. The result showed that the amount of $\mathrm{CV}$ adsorbed decreased with the increase of temperature. It suggested that the adsorption occurred due to physical interaction and it was favorable at lower temperature. The value of activation energy $\mathrm{E}_{\mathrm{a}}\left(11.27 \mathrm{~kJ} \mathrm{~mol}^{-1}\right)$ revealed that adsorption process was spontaneous and exothermic in nature. The adsorption of crystal violet by peanut shell suggests that this adsorbent may be evaluated for removal of other dyes produced and/or used in pharmaceutical process industries.
\end{abstract}

Key words: Peanut shell, Crystal Violet, Adsorption, Equilibrium, Kinetics.

\section{Introduction}

With the urban and mainly the industrial growth, environmental problems have become more frequent and more critical. The textile industries stand out among the industries that produce effluents with high polluting load. The disposal of coloured wastes such as dyes and pigments into receiving waters damages the environment, as they are carcinogenic and toxic to human and aquatic life. Due to low biodegradation of dyes, a conventional biological treatment process is not very effective in treating dye wastewater. The adsorption process is one of the effective methods for removal dyes from waste effluent (Robinson et al., 2001). Many adsorbents such clay, activated carbon etc have shown excellent adsorption efficacy for organic compounds. A number of low cost, commercially available adsorbents had been used for the removal of dyes from coloured wastewater (Gupta, 2009). However, the adsorption capacities of all the above adsorbents are not satisfactory. More new materials are to be explored to find out potential adsorbents for organic pollutants. Removal of hazardous dye from wastewater by non-conventional bio-adsorbent prepared from waste materials has created attraction among the researchers. Some naturally abundant biomass and industrial byproducts such as baggase, banana pith, rice hull, water hyacinth root, marine alga etc. have been successfully utilized as biosorbents to remove pollutants from waste water (Raghuvanshi et al., 2004; Namasivayam, 1992; Nawar, 1989; Low et al., 1995; Rubin et al., 2005). This has led many workers to search for the use of cheap, biodegradable and efficient adsorbent materials.

Peanuts are one of the leading food crops produced in Bangladesh today. Most peanuts are separated from the shells prior to processing into value added products. It is an agricultural waste material abundantly available in our country. A report shows that peanut shells contain about $37.0 \%$ cellulose and $28.8 \%$ lignin (Kerr et al., 2006). These are biodegradable, can be utilized as animal food filler, absorbents, or carriers for pesticides or fertilizers, although they are often land filled. Literature survey 
showed that the possibility of peanut shells as a potential biosorbent is appealing (Li et al., 2007; Brito et al., 2010).

Crystal violet (CV), a cationic dye (Figure 1), is the primary stain used in the Gram staining technique for differentiation of Gram-negative versus Gram-postive bacteria. Crystal (gentian) violet was formerly used as a preservative, fungicide, bactericide and anthelmintic and as an indicator dye in veterinary preparations and animal feeds. The use of crystal violet is of great concern because of its demonstrated carcinogenicity and the possible risk to public health (APVMA, 1994).

The present study has been designed to investigate the potential use of peanut shells, a non-conventional biosorbent, for the removal of crystal violet from aqueous solution. For this purpose batch adsorption experiments have been carried out under varying experimental conditions such as contact time, initial concentration of crystal violet solution, $\mathrm{pH}$ and temperature of the solution.

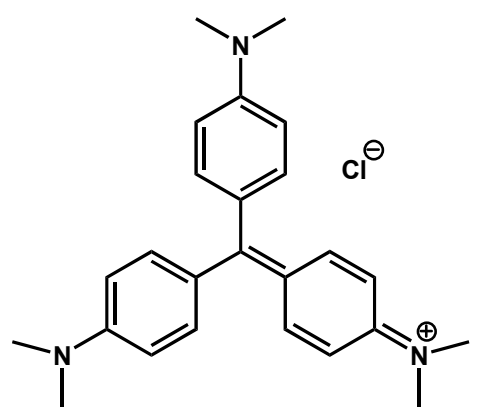

Figure 1. Molecular structure of crystal violet (CV).

\section{Materials and Methods}

Crystal violet (CV) used in this study was purchased from AG Merck, Germany and used without further purification. It has molecular formula $\mathrm{C}_{25} \mathrm{~N}_{3} \mathrm{H}_{30} \mathrm{Cl}$ and mol. wt. $407.979 \mathrm{~g} \mathrm{~mol}^{-1}$. The dye stock solution was prepared by dissolving accurately weighed dye in deionized distilled water. The experimental solutions were obtained by diluting the stock solution in accurate proportions to the needed initial concentrations. The other reagents used in this study were of pure analytical grade.

Preparation of adsorbent: The raw peanut shells were collected from waste of local market. The raw shells were repeatedly washed with distilled water to remove the dirt and soluble materials and dried in air. Then the peanut shells were crushed into small pieces. To make it free from colouring materials, wax and other impurities, the peanut shells were extracted with petroleum ether for about 3.0 hours. The extractive free peanut shells were treated with warm distilled water. Then the sample was dried in the oven at $70^{\circ} \mathrm{C}$ for about 24 hours. The dried shell was ground using a grinding machine and sieved through a set of metallic sieves ranging from $212 \sim 300 \mu \mathrm{m}$. The material was denoted as 'PnS' and kept in air tight container for use as adsorbent in the present studies.

Determination of zero point charge $\mathrm{pH}\left(\mathrm{pH}_{z p c}\right)$ of $P n S$ : The $\mathrm{pH}_{\mathrm{ZPC}}(\mathrm{pH}$ at zero point charge) of peanut shells (PnS) was determined by pH-metric titration (Huang, 1978a; Huang, 1978b; Faust, 1987; Hossain, 1999; Begum, 2012). About $0.5 \mathrm{~g}$ of PnS adsorbent was added to four identical portions of $50.0 \mathrm{~mL}$ of $0.01 \mathrm{M} \mathrm{NaCl}$ solution at $\mathrm{pH} 7$. The mixtures were agitated for 24 hours in thermostatic shaker (HAKKE, SW B-2, Fisons Ltd. Germany). Two bottles of suspension were titrated with $0.05 \mathrm{M} \mathrm{HCl}$ and $0.05 \mathrm{M} \mathrm{NaOH}$, respectively using micro burette. During the titration, the constant $\mathrm{pH}$ values were noted after each aliquot of titrant (acid or alkali) addition. From other two bottles, the supernatants after filtration were titrated with acid and alkali as described above. The net titration curve was obtained by finding the difference between the titration curves of the supernatants and that of the sample with adsorbent (Figure 2). The net titration curves meet at a point, which is defined as the $\mathrm{pH}_{\mathrm{ZPC}}$ of PnS.

\section{Adsorption study}

Determination of optimum $\mathrm{pH}$ for adsorption study: For the determination of optimum $\mathrm{pH}, 0.05 \mathrm{~g} \mathrm{PnS}$ was taken in each of the eight bottles. $50 \mathrm{~mL}$ of $100 \mathrm{mg} \mathrm{L}^{-1}$ $\mathrm{CV}$ solution of different $\mathrm{pHs}$ (ranging from 3.0 to 10.0) was taken in each bottle. The bottles were placed in a thermostatic mechanical shaker (HAKKE, SW B-2, Fisons Ltd. Germany), maintained at $30^{\circ} \mathrm{C}$ and were shaken continuously for six hours. The reagent bottles were successively withdrawn after shaking for definite time and the solutions were centrifuged. Then the $\mathrm{pHs}$ of the solutions were measured using a $\mathrm{pH}$-meter (HANNA instrument, Romania). These $\mathrm{pHs}$ were different from the initial values. The difference of $\mathrm{pH}$ from the initial values was estimated as $\Delta \mathrm{pH}$. The plot of $\Delta \mathrm{pH}$ vs. initial $\mathrm{pH}$ 
produces a curve which intersects the $\mathrm{X}$-axis at a point as shown in Figure 3.

Estimation of the equilibrium time: The equilibrium time of the adsorption of crystal violet $(\mathrm{CV})$ on peanut shell $(\mathrm{PnS})$ was estimated at $\mathrm{pH}$ 7.6. Here, $0.05 \mathrm{~g}$ of $\mathrm{PnS}$ (particle size: $212-300 \mu \mathrm{m}$ ) and $40 \mathrm{~mL}$ of $25 \mathrm{mg} \mathrm{L}^{-1}$ crystal violet solution were used in each of the 12 bottles. The $\mathrm{pH}$ of the solution was adjusted to 7.6 and the bottles were shaken in a thermostatic mechanical shaker for 6 hours at $30^{\circ} \mathrm{C}$. For blank $0.05 \mathrm{~g}$ of $\mathrm{PnS}$ and $40 \mathrm{~mL}$ of DDW solution added in a bottle and was shaken for 6 hours at $30^{\circ} \mathrm{C}$. After a definite interval of time each bottle was withdrawn from the shaker. The supernatant of the bottle was transferred and centrifuged repeatedly until a clear liquid was obtained. The absorbance of the clear solution was measured spectrophotometrically at $\lambda_{\max }$ $582.0 \mathrm{~nm}$. Using the same procedure and conditions the experiments were carried out at different concentrations such as 50, 75, 100, 150, 200 and $300 \mathrm{mg} \mathrm{L}^{-1}$ crystal violet solution and the equilibrium experiments were also carried out at different temperatures such as 30, 40 and $55^{\circ} \mathrm{C}$ using $100 \mathrm{mg} \mathrm{L}^{-1}$ crystal violet solution. The amount of $\mathrm{CV}$ adsorbed at time $\mathrm{t}\left(\mathrm{mg} \mathrm{g}^{-1}\right), \mathrm{q}_{\mathrm{t}}$, on $\mathrm{PnS}$ was calculated by a mass balance relationship,

$$
\mathrm{q}_{\mathrm{t}}=\left(\mathrm{C}_{0}-\mathrm{C}_{\mathrm{t}}\right) \mathrm{V} / \mathrm{m}
$$

At equilibrium time, the amount of $\mathrm{CV}$ adsorbed $\mathrm{q}_{\mathrm{e}}$ $\left(\mathrm{mg} \mathrm{g}^{-1}\right)$, was calculated by the following relationship,

$$
\mathrm{q}_{\mathrm{e}}=\left(\mathrm{C}_{0}-\mathrm{C}_{\mathrm{e}}\right) \mathrm{V} / \mathrm{m}
$$

where, $\mathrm{C}_{0}$ is the initial dye concentration in the solution ( $\left.\mathrm{mg} \mathrm{L}^{-1}\right), \mathrm{C}_{\mathrm{t}}$ is the residual dye concentration in the solution at any time $\mathrm{t}\left(\mathrm{mg} \mathrm{L}^{-1}\right), \mathrm{C}_{\mathrm{e}}$ is the residual dye concentration in the solution at equilibrium time $\left(\mathrm{mg} \mathrm{L}^{-1}\right)$, $\mathrm{V}$ is the solution volume $(\mathrm{L})$ and $\mathrm{m}$ is the mass of peanut shell $(\mathrm{g})$. The plots of amount adsorbed, $\mathrm{q}_{\mathrm{t}}\left(\mathrm{mg} \mathrm{g}^{-1}\right)$ versus the time (min) of adsorption has been presented in Figure 4 and 5.

Adsorption isotherms of $\mathrm{CV}$ on PnS at different $\mathrm{pHs}$ : Adsorption isotherms were carried out on PnS using different initial concentrations of crystal violet from 25 to $400 \mathrm{mg} \mathrm{L}^{-1}$ at $\mathrm{pH} 7.6$ and $30^{\circ} \mathrm{C}$. Each solution $(40 \mathrm{~mL})$ was taken in 8 bottles. The bottles were shaken in thermostatic mechanical shaker at $30^{\circ} \mathrm{C}$ for 4.0 hours. The bottles were withdrawn at the stipulated time from the shaker and supernatant was transferred to the centrifuge tube for centrifugation. Following the same procedure the adsorption isotherms were performed at $\mathrm{pHs} 3,4,5,6$, and 9. In all cases, the $\mathrm{pH}$ of the solution was adjusted by using small amount of $\mathrm{NaOH}$ or $\mathrm{HCl}$ without affecting the volume of the solution. The absorbance of the clear solution was measured spectrophotomtrically using $\lambda_{\max }$ $585.0 \mathrm{~nm}$ for $\mathrm{pH} 3$ to 6 and $\lambda_{\max } 582.0 \mathrm{~nm}$ for $\mathrm{pH} 7.6$ to 9 . Plots of amount adsorbed at equilibrium, $\mathrm{q}_{\mathrm{e}}\left(\mathrm{mg}^{-1}\right)$ versus equilibrium concentration, $\mathrm{C}_{\mathrm{e}}\left(\mathrm{mg} \mathrm{L}^{-1}\right)$ at different pHs are shown in Figure 6.

\section{Results and Discussion}

The effluent produced from the textile industries and many other chemical industries is heavily contaminated with dyes and others coloring impurities. Various types of techniques have been employed to decolorise the wastewater such as adsorption, chemical flocculation, chemical oxidation and biological techniques. The effectiveness of adsorption for dye removal from wastewater has made it an ideal alternative to other expensive treatment methods. Low cost adsorbents originated from natural sources have been highlighted in recent year in order to remove contaminants from water.

In all regions of Bangladesh, peanut is grown abundantly. This agro-production generates a large amount of shells as a waste material, about one fourth of the total production. The majority of peanut shells are burned or dumped to deteriorate naturally.

Preparation of adsorbents from peanut shells is economically profitable due to its low cost but high availability in our country. In the present study, the potential use of peanut shell, a non-conventional biosorbent, was investigated for the removal of crystal violet $(\mathrm{CV})$ from aqueous solution. 
Determination of zero point charge $\mathrm{pH}\left(\mathrm{pH}_{Z P C}\right)$ of $P n S$ : Determination of zero point charge of biosorbent is important in elucidating biosorption mechanism. Biosorption of cations is favour at $\mathrm{pH}>\mathrm{pH}_{\mathrm{ZPC}}$, while anion biosorption is favoured at $\mathrm{pH}<\mathrm{pH}_{\mathrm{ZPC}}$. The specific biosorption of cations shifts $\mathrm{pH}_{\mathrm{ZPC}}$ towards lower values whereas the specific biosorption of anions shifts $\mathrm{pH}_{\mathrm{ZPC}}$ towards higher values. The surface zero point charge $\left(\mathrm{pH}_{\mathrm{ZPC}}\right)$ of $\mathrm{PnS}$ was determined by $\mathrm{pH}$-metric titration. The result is presented in Figure 2. The surface zero point charge $\left(\mathrm{pH}_{\mathrm{ZPC}}\right)$ of $\mathrm{PnS}$ was found to be 6.27 in $0.01 \mathrm{M}$ $\mathrm{NaCl}$ solution.

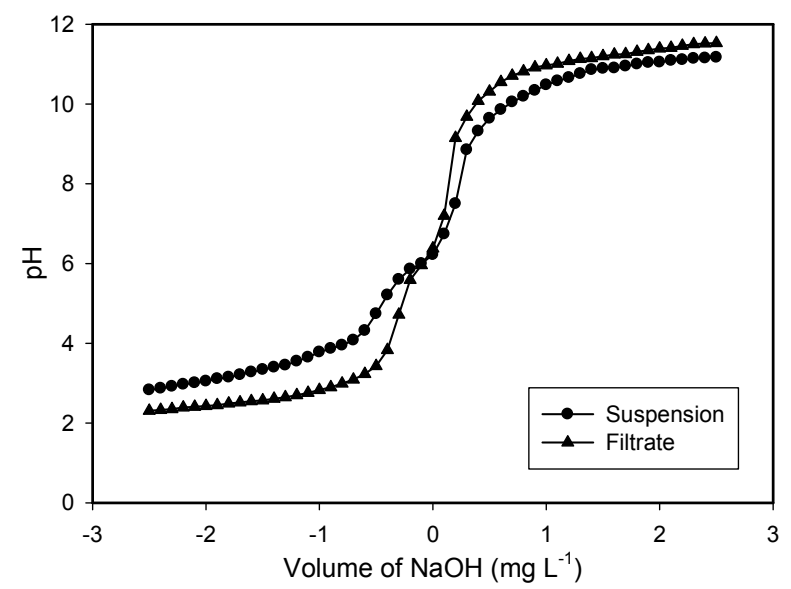

Figure 2. $\mathrm{pH}$ metric titration curve of $\mathrm{PnS}$ in $0.01 \mathrm{M} \mathrm{NaCl}$ solution.

\section{Adsorption studies}

Optimization of $\mathrm{pH}$ : Adsorption property of an adsorbent significantly depends on the $\mathrm{pH}$ of the solution. Before measuring the equilibrium time for the adsorption of $\mathrm{CV}$ on $\mathrm{PnS}$, the optimum $\mathrm{pH}$ of the solution used for adsorption experiments was determined. The results of optimum $\mathrm{pH}$ estimation are shown in Figure 3. To determine the optimum $\mathrm{pH}$ for adsorption of $\mathrm{CV}$ on $\mathrm{PnS}$, $\mathrm{pH}$ of the solution was varied from 2 to 10 . From the plot $\Delta \mathrm{pH}$ vs. initial $\mathrm{pH}$ (Figure 3), the curve was very close to zero line at $\mathrm{pH} 2.0$ and intersects to the zero line at $\mathrm{pH}$ 7.6. No change in these two pHs were observed before and after adsorption of $\mathrm{CV}$ on $\mathrm{PnS}$. The $\mathrm{pH}_{\mathrm{ZPC}}$ for $\mathrm{PnS}$ was estimated and found to be 6.27 . The $\mathrm{pH}$ values higher than $\mathrm{pH}_{\mathrm{zpc}}$ (6.27), the number of negatively charged adsorbent sites increases, so interaction between the negatively surface charged adsorbent and positively charged dye will be favorable. For this reason, $\mathrm{pH} 7.6$ was selected as optimum $\mathrm{pH}$, for the adsorption experiments of $\mathrm{CV}$ from aqueous solution on PnS.

Estimation of equilibrium time: For the estimation of equilibrium time, the adsorption experiment was carried out at $\mathrm{pH} 7.6$ and $30^{\circ} \mathrm{C}$ using the concentration of $\mathrm{CV}$ solution $50,75,100,150,200$ and $300 \mathrm{mg} \mathrm{L}^{-1}$. The amount of PnS taken for each experiment was $0.05 \mathrm{~g}$. Very rapid adsorption was found during the adsorption time of 60 minute. Then the adsorption progresses very slowly. Only 2 to $10 \%$ adsorption occurs up to 4 hours adsorption time on PnS, shown in Figure 4. During the estimation of equilibrium time, it was observed that removal of $\mathrm{CV}$ on $\mathrm{PnS}$ was found to be approximately constant within 4.0 hours for all concentrations, shown in Figure 4. The amount of CV adsorbed on PnS was found to be $195.5 \mathrm{mg} \mathrm{g}^{-1}$ from $300 \mathrm{mg} \mathrm{L}^{-1}$ of dye solution.

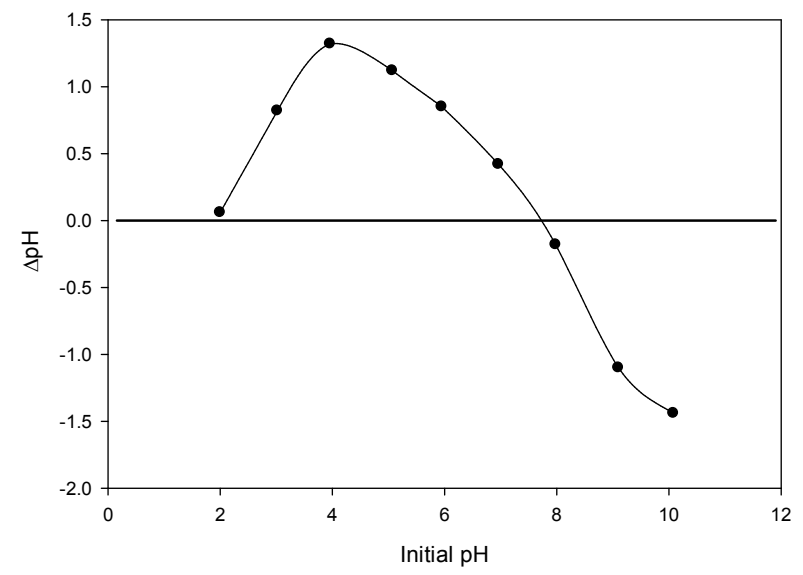

Figure 3. Plot of $\Delta \mathrm{pH}$ vs different initial $\mathrm{pHs}$ of $\mathrm{CV}$ solution.

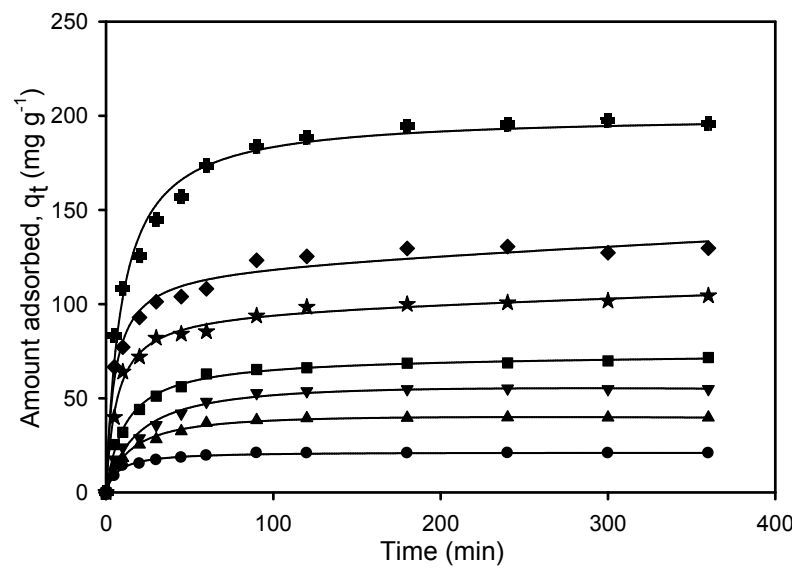

Figure 4. Overlay of amount adsorbed versus time for the estimation of equilibrium time with different initial 
concentrations of $\mathrm{CV}$ on $\mathrm{PnS}\left(\bullet \rightarrow 25 \mathrm{mg} \mathrm{L}^{-1}, \boldsymbol{\Delta} \rightarrow 50 \mathrm{mg}\right.$ $\mathrm{L}^{-1}, \mathbf{\nabla} \rightarrow 75 \mathrm{mg} \mathrm{L}^{-1}, \mathbf{\square} \rightarrow 100 \mathrm{mg} \mathrm{L}^{-1}, \star \rightarrow 150 \mathrm{mg} \mathrm{L}^{-1}$, $\leftrightarrow 200 \mathrm{mg} \mathrm{L}^{-1}$ and $\boldsymbol{+} \rightarrow 300 \mathrm{mg} \mathrm{L}^{-1}$ ).

Effect of initial concentration of $C V$ solution: The initial concentration provides an important force to overcome all mass transfer resistances of all molecules between the aqueous and solid phases (Ho et al., 2005; Doğan et al., 2006). Figure 4 shows the effect of initial concentration on contact time of $\mathrm{CV}$ adsorbed by $\mathrm{PnS}$. The adsorption increases with increase of initial concentration of $\mathrm{CV}$ solution. In a dilute solution the driving force for the adsorption of adsorbate molecules is van dar Waals force and electrostatic attraction. The adsorption of dye onto PnS was found to be rapid at the initial period of contact time and then to slow down with increasing in contact time. This was caused by attractive forces between adsorbate and adsorbent (van der Waals forces and electrostatic attractions); fast diffusion onto external surface of adsorbent was followed by fast pore diffusion into the intraparticle matrix. The increases in loading capacity of the adsorbent with relation to dye ions are probably due to a high driving force for mass transfer. In fact the more concentrated the solution, the higher the intraparticle diffusion greater the adsorption (Weng, 2006). In other words increases in the surface loading led to decreases on the adsorption rate. Generally when adsorption involves a surface reaction process, the initial adsorption is rapid. Then a slower adsorption would follow as the available adsorption sites gradually decreases (Bulut, 2006).

Effect of temperature: The effect of temperature on the adsorption of $\mathrm{CV}$ on $\mathrm{PnS}$ in the range of 30 to $55^{\circ} \mathrm{C}$ was shown in Figure 5. It was observed that the amount of $\mathrm{CV}$ adsorbed onto $\mathrm{PnS}$ decreases with increasing temperature from 30 to $55^{\circ} \mathrm{C}$, indicates that adsorption capacity depends on temperature (Figure 5). The decrease in adsorption with temperature suggests that the adsorption occurs due to physical interaction.

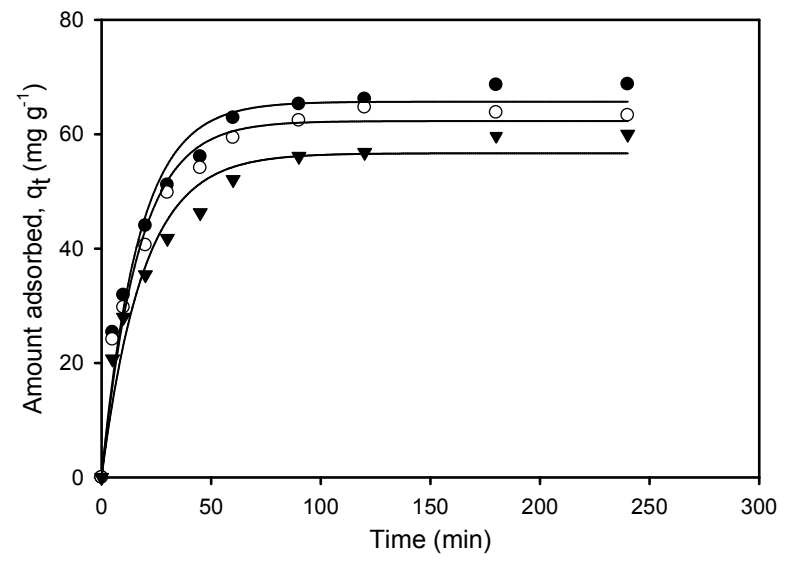

Figure 5. A plot of amount adsorbed versus time for the estimation of equilibrium time with different temperatures of $\mathrm{CV}$ solution $\left(\bullet 30^{\circ} \mathrm{C}, \mathrm{O} \rightarrow 40^{\circ} \mathrm{C}\right.$ and $\left.\boldsymbol{\nabla} \rightarrow 55^{\circ} \mathrm{C}\right)$.

Adsorption isotherms: The adsorption isotherm indicates how the dye molecules distribute between the liquid phase and the solid phase when the adsorption process reaches an equilibrium state. The analysis of the isotherm data by fitting them to different isotherm models is an important step to find the suitable model that can be used for designing the adsorption purpose. The models developed by Langmuir and Freundlich are the most frequently employed to describe the experimental data of adsorption isotherms (Langmuir, 1916; Freundlich, 1906). In this investigation, those two models are used to describe the relationship between the monolayer and multilayer adsorption process at equilibrium.

The adsorption isotherms of $\mathrm{CV}$ on $\mathrm{PnS}$ at six different $\mathrm{pHs}$ and $30^{\circ} \mathrm{C}$ were studied and the results are shown in Figure 6. Under all conditions amount adsorbed increases with the increase of equilibrium concentration. The experimental data of six isotherms have been found to be fit into Langmuir isotherm (Figure 7). Scattering results are obtained for Freundlich plot with regression values 0.8286 to 0.9783 (Figure 8 ), where as regression values for Langmuir adsorption isotherms are 0.9847 to 0.9931 (Figure 7). The Langmuir and Freundlich adsorption parameters are given in Table 1 . The monolayer capacity for $\mathrm{CV}$ is found to be $147.25,161.00,175.20,198.49$, 245.63 and $246.18 \mathrm{mg} \mathrm{g}^{-1}$ at $\mathrm{pH} 3.0,4.0,5.0,6.0,7.6$ and 9.0 , respectively within a concentration range 25 to 400 $\mathrm{mg} \mathrm{L}{ }^{-1}$. 


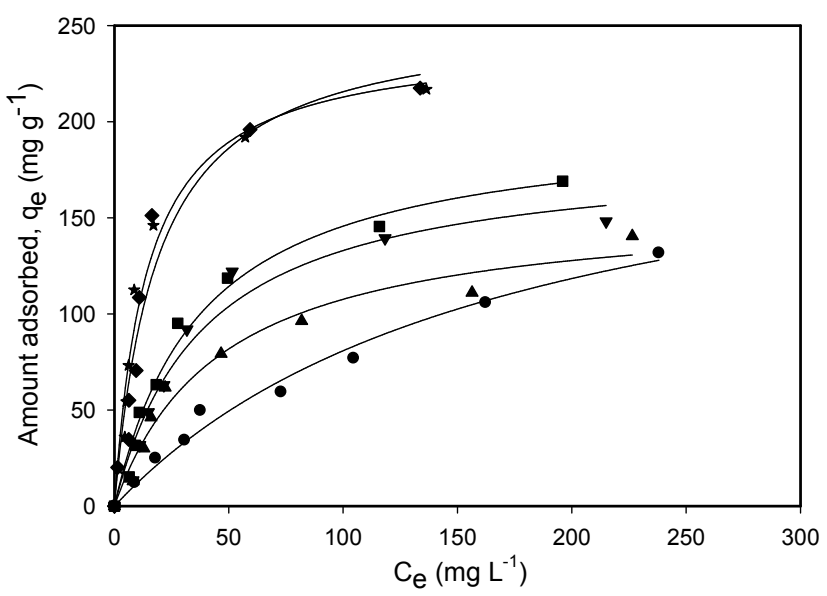

Figure 6. Overlay plot of adsorption isotherms of $\mathrm{CV}$ on $\mathrm{PnS}$ at

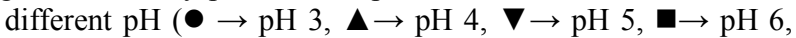
$\star \rightarrow \mathrm{pH} \mathrm{7.6, \diamond} \rightarrow \mathrm{pH} 9)$.

Effect of solution $p H$ on adsorption: The initial solution $\mathrm{pH}$ has been recognized as one of the most important parameters affecting any sorption process. It influences the biosorption process by affecting the surface charge of adsorbent, the degree of ionization and speciation of the adsorbate. Further, it is also directly related with competition ability of hydrogen ions with adsorbate ions to active sites on the adsorbent surface. Adsorption of $\mathrm{CV}$ onto $\mathrm{PnS}$ as function of $\mathrm{pH}$ is shown in Figure 9. At low solution $\mathrm{pH}$, the amount of dye adsorbed on PnS was found to be low. At $\mathrm{pH} 3$, the amount of $\mathrm{CV}$ adsorbed onto PnS was found to be $147.25 \mathrm{mg} \mathrm{g}^{-1}$. The adsorption of $\mathrm{CV}$ increases when the $\mathrm{pH}$ of the dye solution was increased and reaches maximum $(245.63 \mathrm{mg}$ $\mathrm{g}^{-1}$ ) at approximately $\mathrm{pH}$ values of 7.6. This result can be explained by considering the cationic nature of the dyes. Low $\mathrm{pH}$ values between 3 and 5 were unfavorable for $\mathrm{CV}$ adsorption by PnS because of the presence of an excess of hydronium $\left(\mathrm{H}_{3} \mathrm{O}^{+}\right)$ions that competes with positively charged dye for the adsorption sites. At acidic $\mathrm{pH}$ values, the number of negatively charged adsorbent sites decreased and apparently did not favor the adsorption of positively charged dye. For $\mathrm{pH}$ values higher than $\mathrm{pH}_{\mathrm{ZPC}}$

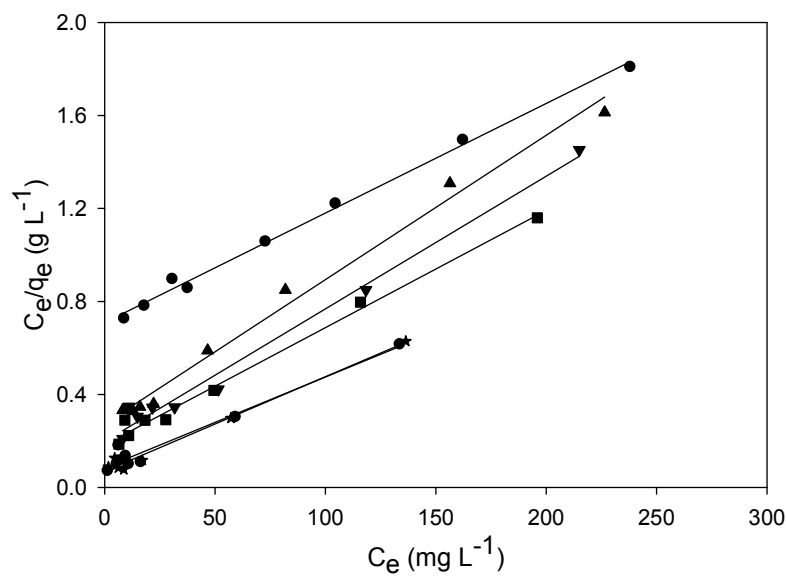

Figure 7. Langmuir adsorption isotherms of $\mathrm{CV}$ on $\mathrm{PnS}$ at $30^{\circ} \mathrm{C}$ and different $\mathrm{pHs}(\bullet \rightarrow \mathrm{pH} 3, \boldsymbol{\Delta} \rightarrow \mathrm{pH} \mathrm{4,} \boldsymbol{\nabla} \rightarrow \mathrm{pH} 5, \boldsymbol{a} \rightarrow \mathrm{pH}$ $6, \star \rightarrow \mathrm{pH} \mathrm{7.6, \diamond} \rightarrow \mathrm{pH} 9)$

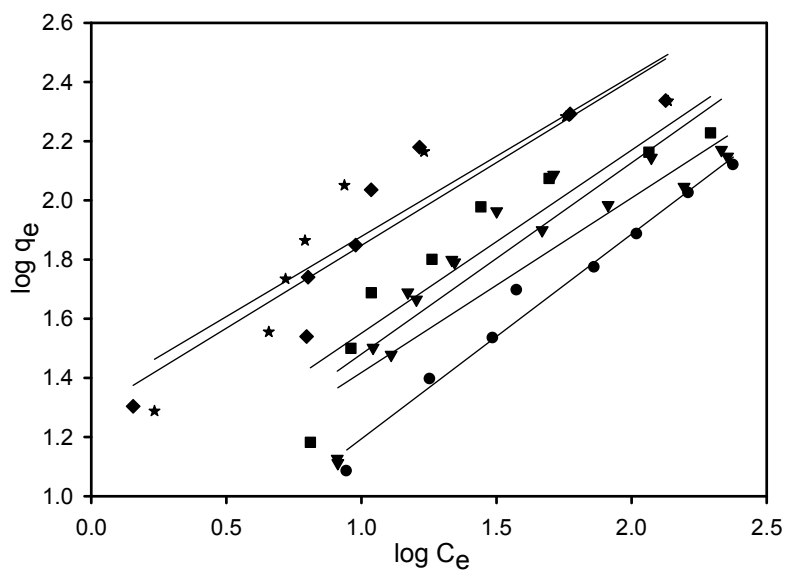

Figure 8. Freundlich adsorption isotherms of $\mathrm{CV}$ on $\mathrm{PnS}$ at $30^{\circ} \mathrm{C}$

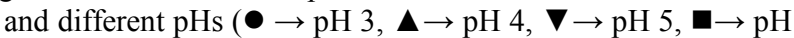
$6, \star \rightarrow \mathrm{pH} \mathrm{7.6}, \diamond \mathrm{pH} 9)$

for $\mathrm{PnS}\left(\mathrm{pH}_{\mathrm{ZPC}}=6.27\right)$ shown in Figure 2, the number of negatively charged adsorbent sites increases and consequently higher amount of $\mathrm{CV}$ is adsorbed by $\mathrm{PnS}$. This observation makes it possible to conclude that the adsorption mechanism is based on interactions between the negatively surface charged adsorbent and positively charged $\mathrm{CV}$.

Table 1. Langmuir and Freundlich parameters of adsorption of CV on PnS at different pHs.

\begin{tabular}{ccccc}
\hline & \multicolumn{2}{c}{ Langmuir } & \multicolumn{2}{c}{ Freundlich } \\
\cline { 2 - 5 } $\mathrm{pH}$ & $\mathrm{r}^{2}$ & $\begin{array}{c}\mathrm{q}_{\mathrm{m}} \\
\left(\mathrm{mg} \mathrm{g}^{-1}\right)\end{array}$ & $\mathrm{r}^{2}$ & $\begin{array}{c}\mathrm{K}_{\mathrm{F}} \\
\left(\mathrm{L} \mathrm{mg}^{-1}\right)\end{array}$ \\
\hline 3.0 & 0.9953 & 147.25 & 0.9781 & 3.17 \\
4.0 & 0.9897 & 161.00 & 0.8418 & 6.72 \\
5.0 & 0.9859 & 175.20 & 0.7992 & 6.81 \\
6.0 & 0.9913 & 198.49 & 0.8504 & 8.54
\end{tabular}




\begin{tabular}{lllll}
7.6 & 0.9882 & 245.63 & 0.8577 & 19.39 \\
9.0 & 0.9957 & 246.18 & 0.8394 & 21.67 \\
\hline
\end{tabular}

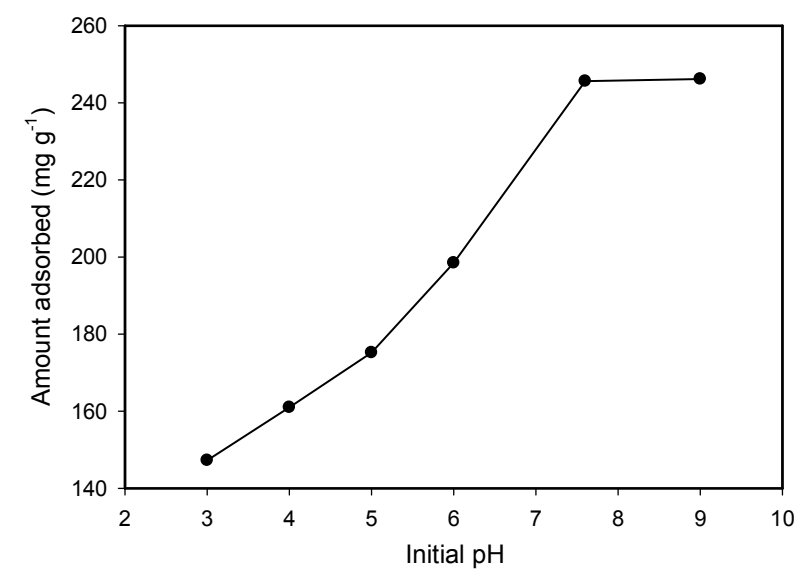

Figure 9. A plot of amount adsorbed vs initial $\mathrm{pH}$ of $\mathrm{CV}$ solution.

Adsorption kinetics: The data obtained from the estimation of equilibrium time for the adsorption of $\mathrm{CV}$ on PnS were fitted in both Lagergren's pseudo first-order kinetic equation (Lagergren, 1898) and Ho's pseudo second-order kinetic equation (Ho, 1999) as shown below: Pseudo-first order:

$$
\log \left(q_{e}-q_{t}\right)=\log q_{e}-\left(k_{1} / 2.303\right) t
$$

Pseudo-second order:

$$
\mathrm{t} / \mathrm{q}_{\mathrm{t}}=1 /\left(\mathrm{k}_{2} \mathrm{q}_{\mathrm{e}}^{2}\right)+\left(1 / \mathrm{q}_{\mathrm{e}}\right) \mathrm{t}
$$

where, $\mathrm{q}_{\mathrm{e}}$ and $\mathrm{q}_{\mathrm{t}}$ are amount of adsorbate adsorbed $\left(\mathrm{mg} \mathrm{g}^{-1}\right)$ at equilibrium time and at any time $\mathrm{t}, \mathrm{k}_{1}$ and $\mathrm{k}_{2}$ are the rate constants of pseudo first-order adsorption $\left(\mathrm{min}^{-1}\right)$ and pseudo second-order adsorption $\left(\mathrm{g} \mathrm{mg}^{-1}\right.$ $\min ^{-1}$ ). The pseudo first-order and pseudo second-order kinetic plots for a constant amount of peanut shells are shown in Figure 10 and 11. The values of the rate constants, regression coefficients and percentage deviation comparing of $\mathrm{q}_{\mathrm{e}}$ values obtained experimentally with those obtained from the first and second order plots are given in Table 2 .

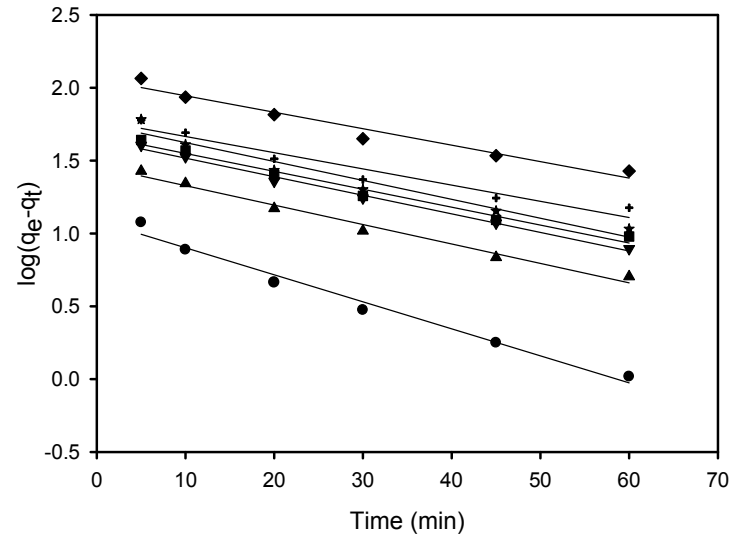

Figure 10. Pseudo-first order kinetic plot for adsorption of $\mathrm{CV}$ on $\operatorname{PnS}\left(\bullet 25 \mathrm{mg} \mathrm{L}^{-1}, \boldsymbol{\Delta} \rightarrow 50 \mathrm{mg} \mathrm{L}^{-1}, \boldsymbol{\nabla} \rightarrow 75 \mathrm{mg} \mathrm{L}^{-1}, \boldsymbol{\square} \rightarrow\right.$ $100 \mathrm{mg} \mathrm{L}^{-1}, \star \rightarrow 150 \mathrm{mg} \mathrm{L}^{-1},+\rightarrow 200 \mathrm{mg} \mathrm{L}^{-1} \diamond \rightarrow 300$ $\mathrm{mg} \mathrm{L}^{-1}$ )

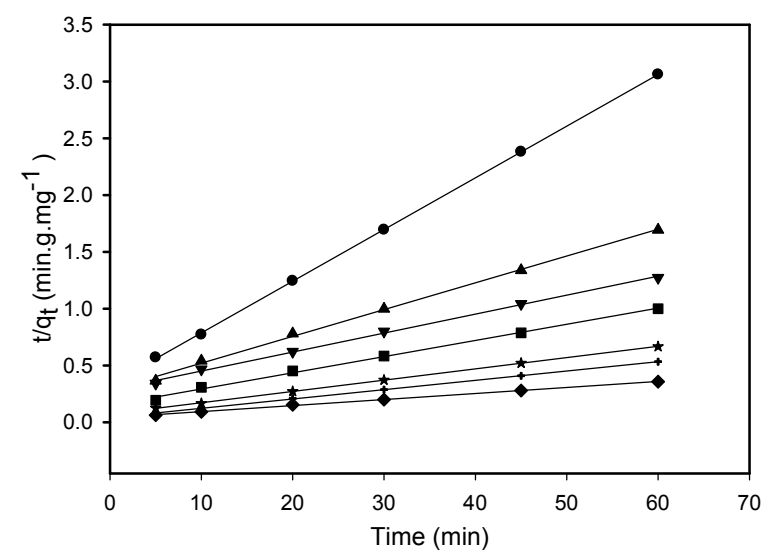

Figure 11. Pseudo-second order kinetic plot for adsorption of CV on $\mathrm{PnS}\left(\bullet 25 \mathrm{mg} \mathrm{L}^{-1}, \boldsymbol{\Delta} \rightarrow 50 \mathrm{mg} \mathrm{L}^{-1}, \boldsymbol{\nabla} \rightarrow 75 \mathrm{mg} \mathrm{L}^{-1}\right.$, $\mathbf{v} \rightarrow 100 \mathrm{mg} \mathrm{L}^{-1}, \star \rightarrow 150 \mathrm{mg} \mathrm{L}^{-1}+\rightarrow 200 \mathrm{mg} \mathrm{L}^{-1}, \diamond \rightarrow$ $300 \mathrm{mg} \mathrm{L}^{-1}$ )

good correlation for the adsorption of $\mathrm{CV}$ on $\mathrm{PnS}$ in contrast to pseudo first-order kinetic model.

Table 2. Rate constant and regression coefficients for first and second order kinetics for adsorption of $\mathrm{CV}$ on PnS at pH 6.7 and $30^{\circ} \mathrm{C}$.

\begin{tabular}{ccccccc}
\hline $\begin{array}{c}\text { Conc. } \\
(\mathrm{mg} / \mathrm{l})\end{array}$ & Order & $\mathrm{r}^{2}$ & $\begin{array}{c}\mathrm{k}_{1}\left(\mathrm{~min}^{-1}\right) / \\
\mathrm{k}_{2}(\mathrm{~g} / \mathrm{mg} / \mathrm{min})\end{array}$ & $\begin{array}{c}\mathrm{q}_{\mathrm{e}}(\mathrm{exp}) \\
(\mathrm{mg} / \mathrm{g})\end{array}$ & $\begin{array}{c}\mathrm{q}_{\mathrm{e}}(\mathrm{plot}) \\
(\mathrm{mg} / \mathrm{g})\end{array}$ & $\begin{array}{c}\% \\
\text { Deviation }\end{array}$ \\
\hline \multirow{2}{*}{25.0} & $1^{\text {st }}$ & 0.9813 & $4.27 \times 10^{-2}$ & 20.85 & 12.22 & 41.39 \\
& $2^{\text {nd }}$ & 0.9999 & $3.12 \times 10^{-3}$ & 20.85 & 21.98 & 5.14 \\
50.0 & $1^{\text {st }}$ & 0.9846 & $3.07 \times 10^{-2}$ & 39.74 & 28.93 & 27.20 \\
75.0 & $2^{\text {nd }}$ & 0.9979 & $9.74 \times 10^{-4}$ & 39.74 & 42.43 & 6.76 \\
& $1^{\text {st }}$ & 0.9938 & $2.94 \times 10^{-2}$ & 54.90 & 44.08 & 19.70
\end{tabular}




\begin{tabular}{ccccccc} 
& & & & & \\
& 2 & 0.9978 & $4.89 \times 10^{-4}$ & 54.90 & 59.92 & 8.37 \\
100.0 & $1^{\text {st }}$ & 0.9805 & $2.83 \times 10^{-2}$ & 69.07 & 47.03 & 31.90 \\
& $2^{\text {nd }}$ & 0.9970 & $6.76 \times 10^{-4}$ & 69.07 & 70.16 & 1.55 \\
150.0 & $1^{\text {st }}$ & 0.9497 & $2.98 \times 10^{-2}$ & 100.77 & 56.71 & 43.72 \\
& $2^{\text {nd }}$ & 0.9998 & $6.79 \times 10^{-4}$ & 100.77 & 100.70 & 0.06 \\
300.0 & $1^{\text {st }}$ & 0.9435 & $2.56 \times 10^{-2}$ & 129.14 & 59.82 & 53.68 \\
& $2^{\text {nd }}$ & 0.9992 & $8.28 \times 10^{-4}$ & 129.14 & 121.69 & 5.76 \\
& $1^{\text {st }}$ & 0.9611 & $2.60 \times 10^{-2}$ & 195.84 & 114.37 & 41.60 \\
& $2^{\text {nd }}$ & 0.9989 & $3.49 \times 10^{-4}$ & 195.84 & 188.23 & 3.88 \\
\hline
\end{tabular}

However, it was seen that the experimentally obtained $\mathrm{q}_{\mathrm{e}}$ value did not match those determined from the first order Lagergren plot and very large deviation existed. Therefore, the pseudo first-order kinetic model did not describe the adsorption results of $\mathrm{CV}$ on peanut shell.

The experimental and plotting $\mathrm{q}_{\mathrm{e}}$ value for pseudo second-order match each other with small deviation. It can be said that pseudo second-order kinetic model provide

Activation energy: From the pseudo-second-order rate constant $\mathrm{k}_{2}$ (Figure 12 and Table 3), the activation energy $\left(E_{a}\right)$ for the adsorption of $\mathrm{CV}$ onto PnS can be estimated by using Arrhenius equation (ln $\mathrm{k}_{2}=\ln \mathrm{A}-\mathrm{E}_{\mathrm{a}} / \mathrm{RT}$ ) [25]. The values of $\ln \mathrm{k}_{2}$ were plotted against $1 / \mathrm{T}$ (Figure 13), and a straight line with slope $\left(-\mathrm{E}_{\mathrm{a}} / \mathrm{R}\right)$ was obtained. The value of $E_{a}$ was presented in Table 3. The chemisorption or physisorption mechanisms are often an important indicator to describe the type of interaction between dye molecule and adsorbent. The physisorption processes usually have energies in the ranges of $4-40 \mathrm{~kJ} \mathrm{~mol}^{-1}$, while higher activation energies $\left(40-400 \mathrm{~kJ} \mathrm{~mol}^{-1}\right)$ suggest chemisorptions (Nollet, 2003). The value of $E_{a}$ from the slope of the plot is found to be $11.27 \mathrm{~kJ} \mathrm{~mol}^{-1}$ (Figure 13). The low value of activation energy further confirms that the adsorption of $\mathrm{CV}$ on PnS occurred due to physical adsorption. Similar observation was found for the adsorption of methylene blue on Brazil nut (Brito et al., 2010).

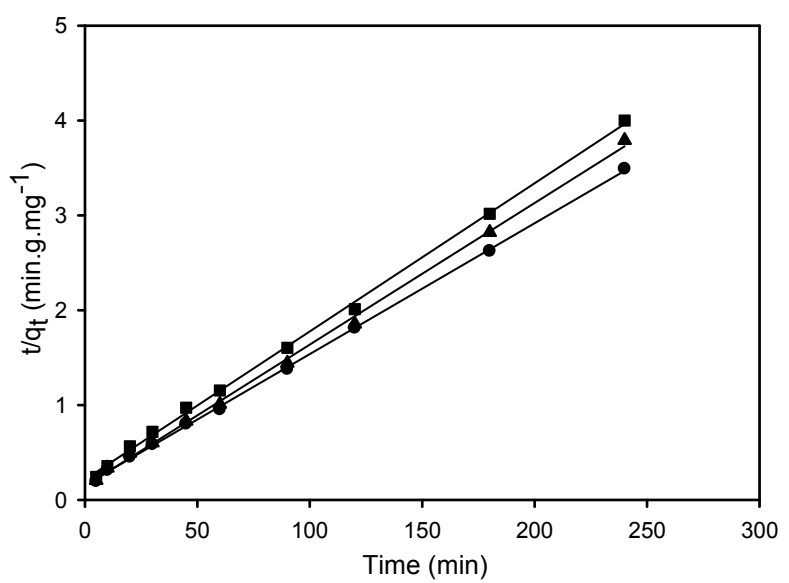

Figure 12. Pseudo second order kinetic plot for adsorption of CV onto $\mathrm{PnS}$ at different temperatures $\left(\bullet 30^{\circ} \mathrm{C}, \boldsymbol{\Delta} \rightarrow 40^{\circ} \mathrm{C}, \boldsymbol{\square} \rightarrow\right.$ $\left.55^{\circ} \mathrm{C}\right)$

Table 3. Pseudo second order kinetic parameters for the adsorption of CV onto PnS.

\begin{tabular}{cccccc}
\hline $\begin{array}{c}\text { Temp } \\
(\mathrm{K})\end{array}$ & $\begin{array}{c}1 / \mathrm{T} \\
\left(\mathrm{K}^{-1}\right) \\
\times 10^{3}\end{array}$ & $\begin{array}{c}\mathrm{k}_{2} \times 10^{4} \\
\left(\mathrm{~g} \mathrm{mg}^{-1}\right. \\
\left.\mathrm{min}^{-1}\right)\end{array}$ & $1 \mathrm{nk}_{2}$ & $\mathrm{r}^{2}$ & $\begin{array}{c}\text { Activation } \\
\text { energy, } \mathrm{E}_{\mathrm{a}} \\
\left(\mathrm{kJ} \mathrm{mol}^{-1}\right)\end{array}$ \\
\hline 303 & 3.356 & 8.683 & 7.049 & 0.9995 & \\
313 & 3.195 & 7.123 & 7.247 & 0.9985 & 11.27 \\
328 & 3.048 & 5.714 & 7.467 & 0.9988 & \\
\hline
\end{tabular}

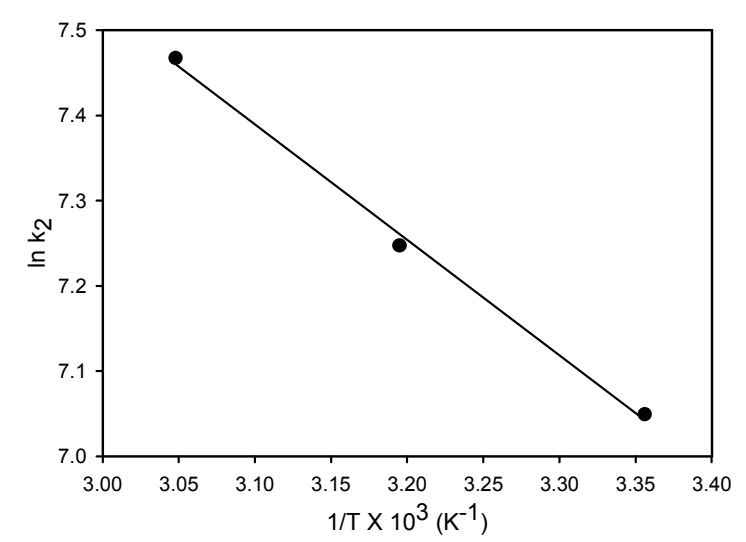

Figure 13. Arrhenius plot for the adsorption of CV on PnS.

\section{Conclusion}


The present study revealed the potential use of peanut shell (PnS), a non-conventional bio-adsorbent from agricultural waste, for the removal of crystal violet (CV), a cationic dye, from aqueous solution. Batch adsorption experiments were carried out using PnS under varying experimental conditions such as contact time, initial dye concentration, temperature and initial $\mathrm{pH}$ of the $\mathrm{CV}$ solution. The amount of adsorption of $\mathrm{CV}$ increased with the increase of initial dye concentration and $\mathrm{pH}$ but decreased with the decrease of temperature. Experimental equilibrium data provided best fit result with the Langmuir isotherm model. The kinetics of the bio-adsorption process followed pseudo second-order kinetic model. The present findings suggest that PnS might be used as an effective and low cost bio-adsorbent for removal of $\mathrm{CV}$ from aqueous solution. It also suggests the possible role of $\mathrm{CV}$ for removal of other dyes and colors produced in pharmaceutical effluents and API industries.

\section{References}

APVMA, 1994. Gazette Notice: cancellation of registration for agricultural products. Australian Pesticides and Veterinary Medicines Authority, 18 Wormald Street, Symonston, ACT, 2609, Australia.

Begum, H.A., Mondal, A.K. and Muslim, T. 2012. Adsorptive removal of Reactive Black 5 from aqueous solution using chitin prepared from shrimp shells. Bangladesh Pharm. J. 15, 145-152.

Brito, S.M., de, O., Andrade, H.M.C., Soares, L.F. and Azavedo, R.P. de. 2010. Brazil nut shells as a new biosorbent to removal of methylene blue and indigo carmin from aqueous solutions. J. Hazard. Mater. 174, 84-92.

Bulut, Y. and Aydın, H. 2006. A kinetics and thermodynamics study of methylene blue adsorption on wheat shells. Desalination, 194, 259-267.

Doğan, M., Alkan, M., Demirbas, Ö., Ozdemir, Y. and Ozmetin, C. 2006. Adsorption kinetics of maxilon blue GRL onto sepiolite from aqueous solutions. Chem. Eng. J. 124, 89101.

Faust, S.D. and Aly, O.M. 1987. Adsorption process for water treatment. Butterworths Publishers, USA,

Freundlich, H.M.F. 1906. Uber die adsorption in losungen. $Z$. Phys. Chem. 57, 85-470.

Gupta, V.K. and Suhas, 2009. Application of low-cost adsorbents for dye removal- a review. J. Environ. Managent. 90, 2313-2342.

Ho, Y.S. and McKay, G. 1999. Pseudo-second order model for sorption processes. Process Biochem. 34, 451-465.
Ho, Y.S., Chiang, T.H. and Hsueh, Y.M. 2005. Removal of basic dye from aqueous solutions using tree fern as a biosorbent. Process Biochem. 40, 119-124.

Hossain, A.K.M.Z., Hossain, M.A., Khanom, F., Begum, H.A., Ehsan, M.Q. and Islam, T.S.A. 1999. Adsorption behaviour of dichlorophenol on alumina. Dhaka Univ. J. Sci. 47, 167175.

Huang, C.P. and Bowers, A.R. 1978a. Use of activated carbon for chromium (VI) removal. Progr. Water Tech. 10, 45-64.

Huang, C.P. and Ostovic, F.B. 1978b. Removal of cadmium (II) by activated carbon adsorption. J. Environ. Eng. 104, 863878.

Kerr, T.J., Windham, W.R., Woodward, J.H., Benner, R. 2006. Chemical Composition and in-vitro digestiblity of thermochemical treated peanut hulls. J. Sci. Food Agr. 37, 632-636.

Lagergren, S. 1898. About the theory of so-called adsorption of soluble substances. Kungliga Svenska Vetenskapsakademiens. Handlingar 24, 1-39.

Langmuir, I. 1916. The constitution and fundamental properties of solids and liquids. Part I. J. Am. Chem. Soc. 38, 22212295.

Li, Q., Zahi, J., Zhang, W., Wang, M. and Zhou, J. 2007. Kinetic study of adsorption of $\mathrm{Pb}$ (II), $\mathrm{Cr}$ (III) and $\mathrm{Cu}$ (II) from aqueous solution by sawdust and modified peanut husk. $J$. Hazard. Mater. 141, 163-167.

Low, S.K., Lee, C.K. and Tan, K.K., 1995. Biosorption of of basic dyes by water hyacinth roots. Bioresour. Technol. 52, 79-83.

Namasivayam, C. and Kanchana, N. 1992. Waste banana pith as adsorbent for colour removal from wastewaters. Chemospere, 25, 1691-705.

Nawar, S.S. and Doma, H.S. 1989. Removal of dyes from effluents using low-cost agricultural by-products. Sci. Total Environ. 79, 271-279.

Nollet, H., Roels, M., Lutgen, P., Van der Meeren, P. and Verstraete, W. 2003. Removal of PCBs from wastewater using fly ash. Chemosphere, 53, 655-665.

Raghuvanshi, S.P., Singh, R. and Kaushik, C.P. 2004. Kinetics study of Methylene Blue dye bioadsorption on baggase. Appl. Ecol. Environ. Res. 2, 35-43.

Robinson, T., McMullan, G., Marchant, R. and Nigam, P. 2001. Remediation of dyes in textiles effluent: a critical review on current treatment technologies with a proposed alternative. Bioresour. Technol. 77, 247-255.

Rubin, E., Rodriguez, P., Herrero, R., Cremades, J., Barbara, I. and de Vicente, M.E.S. 2005. Removal of methylene blue from aqueous solutions using as biosrbent Sargassum muticum: an invasive macroalga in Europe. J. Chem. Technol. Biotechnol. 80, 291-298. 
Weng, C.H. and Pan, Y.F. 2006. Adsorption characteristics of methylene blue from aqueous solution by sludge ash. Colloids Surf. A: Physicochem. Eng. Aspects, 274, 154-162. 